This is the author's final, peer-reviewed manuscript as accepted for publication. The publisher-formatted version may be available through the publisher's web site or your institution's library.

\title{
Application and evaluation of short-term emergency ratings for double-circuit transmission lines
}

S. D. Kim, S. R. Kim, and M. M. Morcos

\section{How to cite this manuscript}

If you make reference to this version of the manuscript, use the following information:

Kim, S. D., Kim, S. R., \& Morcos, M. M. (2012). Application and evaluation of short-term emergency ratings for double-circuit transmission lines. Retrieved from http://krex.ksu.edu

\section{Published Version Information}

Citation: Kim, S. D., Kim, S. R., \& Morcos, M. M. (2012). Application and evaluation of short-term emergency ratings for double-circuit transmission lines. Electric Power Components and Systems, 40(7), 729-740.

Copyright: Copyright @ Taylor \& Francis Group, LLC

Digital Object Identifier (DOI): doi:10.1080/15325008.2012.658598

Publisher's Link: http://www.tandfonline.com/doi/abs/10.1080/15325008.2012.658598

This item was retrieved from the K-State Research Exchange (K-REx), the institutional repository of Kansas State University. K-REx is available at http://krex.ksu.edu 


\title{
Application and Evaluation of Short-term Emergency Ratings for Double-circuit Transmission Lines
}

\author{
S. D. Kim ${ }^{1}$, S. R. Kim², and M. M. Morcos ${ }^{3}$ \\ ${ }^{1}$ Department of Electronic Engineering, Hanbat National University, Daejeon, KOREA \\ ${ }^{2}$ Department of Computer Engineering, Cheongju University, Cheongju, KOREA \\ ${ }^{3}$ Department of Electrical and Computer Engineering, Kansas State University, \\ Manhattan, KS, USA
}

\begin{abstract}
Emergency ratings have been introduced for operating transmission lines safely and supplying current capacity efficiently, as well as controlling load flow when occurring line faults. In this paper, short-term emergency ratings are calculated by using thermal equilibrium equation for bared conductors in doublecircuit transmission lines. Overhead transmission lines installed in double-circuit have been extensively utilized worldwide to enhance power transmission. Such lines show various advantages in increasing transmission capacity and decreasing power loss as well as being operated flexibly during a contingency. Even when a fault occurs in one circuit, the healthy circuit can supply power continuously during emergency without outage. The utilization of such double-circuit transmission lines during normal and/or emergency operations is described. Maximum normal operating current based on fault duration, maximum allowable temperature of conductor, and thermal line ratings are evaluated. Several performances of dip/clearance affecting short-term emergency rating are also presented.
\end{abstract}

Keywords double-circuit transmission lines, short-term emergency rating, thermal line rating.

\section{INTRODUCTION}

It has become increasingly difficult to build new transmission lines due to the reorganization of power industry, and demand of higher economic management. Many power companies are searching for efficient operation strategies applicable to the present power networks without new investments. Therefore, re-evaluation of available capacity, conductor lifespan and emergency ratings have been taken into account. Consequently, utilities are looking at alternative approaches to up-rate the load capacity (ampacity) for the existing transmission lines [1], [2].

The ampacity of an overhead transmission line is given as a thermal rating of conductor 
calculated by a specific conductor temperature. In particular, the conductor current for a maximum allowable temperature is defined as static line rating (SLR) [3]. The maximum allowable temperature of conductor is determined based on a specified tensile loss, a suitable dip/clearance margin, or conservative weather conditions [4], [5]. Typically, SLR involves the pre-determination of worst-case weather conditions along the entire line for an extended period of time. This assures that the conductor will not sag below the required safe clearance at any point during the conductor lifespan. On the other hand, dynamic line rating (DLR) is the rating defined as the steady-state load that produces the maximum conductor operating temperature, based on actual loading and weather conditions. Most transmission lines are not designed to carry all the maximum ratings due to contingencies or overloading of the line. Normal operation ratings are usually given below SLR or DLR. Hence there always exists some margin of rating, especially that ratings are increased during a short time interval.

Emergency ratings can be determined by considering both fault duration and limiting temperature/overload rate. Long-term emergency rating (LTER) is the rating through fault durations of several hours; it is based on the steady-state thermal rating of conductor. Shortterm emergency rating (STER) is the rating given for the transmission line to operate safely through shorter fault durations [6], [7]. Hence, both the steady-state characteristics and transient response should be considered in the heat-balance equation. Transient ratings cannot be defined as common standard indices. Most power companies have their own standards for emergency actions before any fault may lead to significant accidents such as widespread outages on transmission networks. Transient line rating is defined as a relative concept of SLR, yet it is only given for a constant-time interval. In particular, such emergency ratings are commonly determined by considering several factors such as SLR, annealing characteristics, and conductor lifespan. Thermal performance of conductors should be taken into consideration as a function of time.

Most utilities have been utilizing double-circuit transmission lines (DCTLs) to enhance the reliability and security for power transmission [8], [9]. Transmission lines cannot operate with full load; therefore, normal operating load is always limited below the maximum design load. Outage of a single circuit of DCTL is normally classified as a single contingency and - for such a contingency - the transmission line should be designed to sustain power supply safely, with an emergency rating. For analysis purposes, emergency ratings of DCTLs are discussed.

\section{EMERGENCY RATINGS OF DOUBLE-CIRCUIT TRANSMISSION LINES}

\subsection{Thermal Line Rating}

If the current and temperature of a bare overhead conductor are denoted by $I$ and $T_{c}$, respectively, the heat-balance equation is given as [3],

$$
m C_{p} \frac{d T_{c}}{d t}+\left[Q_{c}\left(T_{c}\right)+Q_{r}\left(T_{c}\right)-I^{2} R_{a c}\left(T_{c}\right)\right]=Q_{s}
$$

where $m C_{p}$ in $\mathrm{J} / \mathrm{m}^{\circ} \mathrm{C}$ is the total heat capacity of conductor, and $R_{a c}\left(T_{\mathrm{c}}\right)$ is the $\mathrm{AC}$ resistance per unit length in $\mathrm{m} \Omega$ for the given conductor temperature. Also, $Q_{\mathrm{c}}\left(T_{\mathrm{c}}\right), Q_{r}\left(T_{\mathrm{c}}\right)$ and $Q_{s}$ in $\mathrm{W} / \mathrm{m}^{2}$ are the convective heat-loss, radiated heat-loss, and sun heat, respectively. If the conductor reaches the maximum allowable temperature under specified weather conditions, 
the line current in the steady-state could be determined using Eq. (1), which is defined as SLR. In general, SLR is given as a constant current that would yield the maximum allowable conductor temperature for specified weather conditions and conductor characteristics with the assumption that the conductor is in thermal equilibrium.

In this research, the conductor is assumed to be Aluminum Conductor Steel Reinforced (ACSR) and its maximum allowable temperature is specified at $90{ }^{\circ} \mathrm{C}$ [10]. The maximum allowable temperatures of ACSR are in the $50-180{ }^{\circ} \mathrm{C}$ range, depending on weather conditions or ground clearance; hence, the thermal rating of any conductor also varies widely [3]. In most utilities SLR sets the allowable current limit under worst weather conditions. Under normal weather conditions, transmission capacity higher than SLR can be transferred through the same transmission line. All line conductors have marginal capacities higher than the specified ratings. In determining the thermal line rating, there are two major limitations; one is to limit the maximum allowable temperature, and the other is to maintain a sufficient ground clearance. The maximum allowable temperature of conductor is normally selected so as to limit the conductor tension-loss due to annealing, or to hold a required ground clearance.

\subsection{Double-circuit Transmission Lines}

In practice, DCTLs can have different configurations based on the system topology and how they are connected at the two ends of the double circuit line [11]. For example,

- They are not connected to the same bus at either end of the line;

- They are connected to the same bus at only one end of the line; or,

- They are connected to the same bus at each end of the line.

The operation may be different, depending on the system network (loop or radial). Meanwhile, there exist various conditions to be considered. However, the current research is focused only on the analysis and application of short-term line rating, calculated by using transient thermal rating, and DCTL was used as an example transmission line in order to analyze STER performances. For simulation purposes, the following assumptions were made:

(a) The line length is sufficiently short to transfer thermal line rating [1].

(b) At each end, the lines are connected to the same bus [11].

In the present study, it is assumed that two circuits are connected in parallel to the same bus at each end of the line. Associated protection systems are assumed to be installed properly; thus, the healthy circuit operates automatically to carry all loads when one circuit in service breaks down. As a result, one healthy circuit would carry twice the normal operating current before a fault. Therefore, its operating load cannot be preset to maximum allowable load of the utility line.

To guarantee the reliability of power transfer with the assumption that one circuit of DCTL may fail, a maximum operating load per circuit may be limited to half the maximum allowable conductor load and the line can operate safely with one circuit only. However, the 
load can increase further within any suitable levels to ensure safe power delivery. Determination of maximum load depends on various factors such as conductor type/size, dip margin and tower design, line voltage, generator and main transformer capacity. If the transmission line guarantees sufficient dip margin, its rating may be selected as a higher load level. Most utilities have their own criteria for dip limit and tower design; therefore, the solution for determining maximum load or STER may not be unique even in the case of similar transmission lines.

\subsection{Basic Strategy for Emergency Ratings}

Emergency ratings are available to prevent overload lines from breaking down or shedding load. Transient characteristics may be different, depending on weather conditions and normal operating load at the beginning of a fault. Circuit breakers at the line ends may operate automatically as soon as the line current exceeds maximum allowable value. However, most power companies use emergency ratings as pre-calculating levels for stable power transfer.

Emergency rating depends on fault duration, and the protection equipment should be designed based on that rating [6], [7], [10]. There are two different methods to represent emergency ratings: (1) after a maximum allowable temperature of conductor is selected under suitable conditions, the corresponding maximum allowable current is provided or, (2) presetting a suitable overload rate, the maximum allowable current can be determined based on this rate. In this research, the first index for emergency rating (i.e., maximum allowable temperature of emergency) is used.

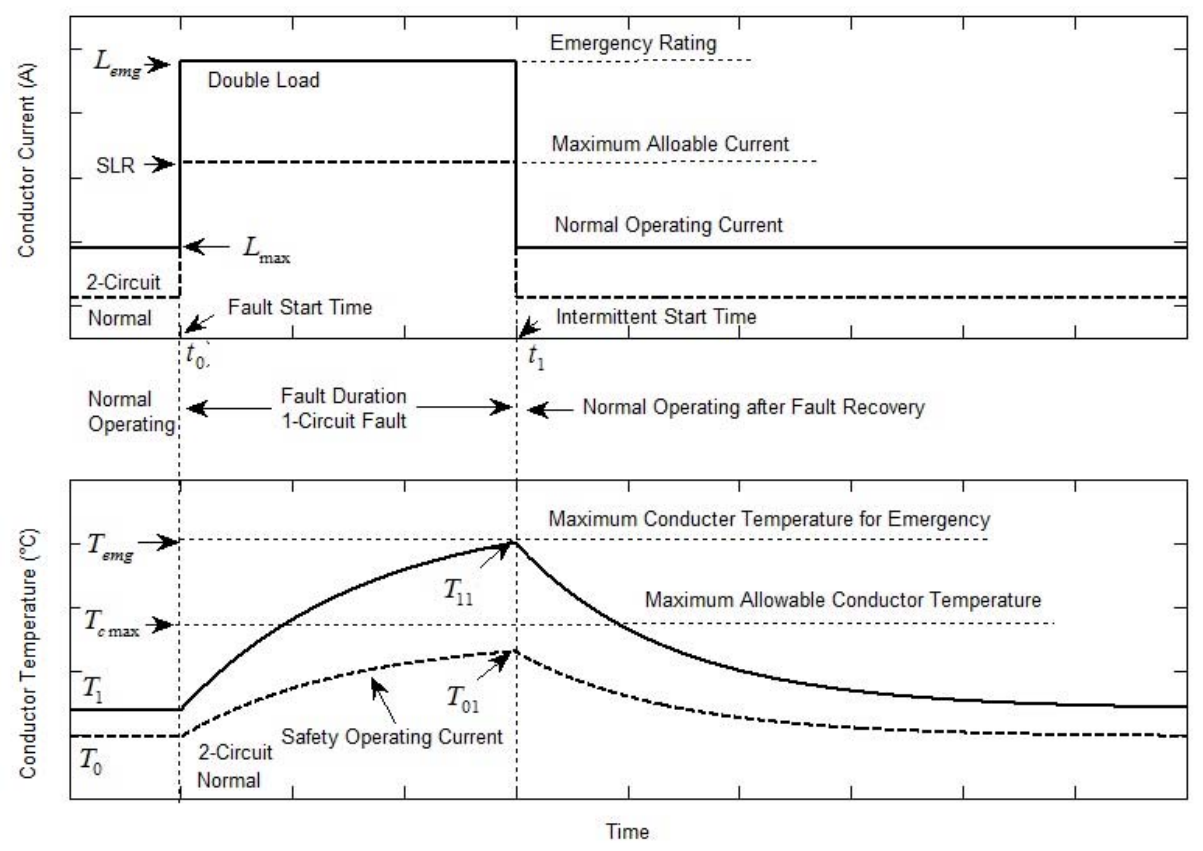

Figure 1. Emergency rating characteristics of DCTL.

In order to illustrate an emergency operation of transmission line, first, one circuit of 
DCTL is assumed to be faulted at time $t_{0}$. The faulted circuit is disconnected from the line instantaneously, the other circuit can transfer all load automatically during the occurrence of fault. In Figure $1, t_{1}$ is the time at which the protection relay operates. If the normal load of one circuit - before fault - is defined as an initial conductor load, $L_{0}$, the healthy circuit must carry double load of $2 L_{0}$. If the fault is eliminated at time $t_{1}$, the faulted line recovers to normal operating status and the transmission line transfers the normal load as before. If the line load is to be limited to $50 \%$ of the maximum level according to operation standards, the maximum value of $L_{0}$ becomes $50 \%$ of SLR. Assuming $L_{0}$ is the maximum normal load per one circuit, the load during the fault is SLR.

From the time the fault starts, conductor temperature begins to rise slowly from $T_{0}$. Since the maximum load of the healthy circuit is equal to SLR - which is a value calculated at the maximum allowable conductor temperature of $90{ }^{\circ} \mathrm{C}$ - the conductor temperature increases towards $90{ }^{\circ} \mathrm{C}$. However, the line fault is removed at $t_{1}$ before the conductor reaches the maximum temperature, then it starts to decrease with time. As a result, the line can be operated safely without failure of the power line. Most power companies have transmission lines not to exceed their respective emergency ratings according to their own operating rules. Such rating is specified as overload rate or limit-temperature of conductor; however, emergency rating is typically given as a load in amperes.

An emergency duration is assumed to be a finite time interval, $t_{1}$, and a maximum allowable temperature for emergency to be $T_{e m g}$, in order to prevent considerable annealing and tension loss of conductor. Hence, conductor temperature should not exceed $T_{\text {emg }}$ during the fault. It can be seen that conductor temperature reaches $T_{e m g}$ at $t_{1}$. Thus, the emergency rating must be determined by considering the transient response of conductor temperature. When adopting emergency rating conditions for DCTL, the maximum load of transmission line must be predetermined. Such operating limits are based on time response, as shown in Figure 1. In DCTL, it is important to specify the maximum operating load, $L_{\text {max }}$, as well as $L_{e m g}\left(=2 L_{\text {max }}\right)$. STER should be considered taking into account both the thermal rating and transient characteristic of conductor, whereas LTER would be used as the rating to only restrict thermal rating of conductor.

\section{DETERMINATION OF EMERGENCY RATINGS}

\subsection{Analytical Conditions}

To verify emergency rating performances, the DCTL under study is assumed to be a 154 $\mathrm{kV}$ transmission line with ACSR $410 \mathrm{~mm}^{2}$ bundle conductors. Most EHV transmission lines commonly use bundle conductors as phase conductors. However, a phase conductor is assumed to be single - for the simplicity of analysis - and is considered with loads (or ratings) focusing on one circuit of DCTL only. The maximum allowable temperature and its maximum current of ASCR $410 \mathrm{~mm}^{2}$ conductor are assumed to be $90{ }^{\circ} \mathrm{C}$ and $848 \mathrm{~A}$, respectively [12].

Generally, the available transmission line capacity is limited by two main factors: the thermal line rating, and the dynamic security rating that relates to the phase-angle difference due to line impedance. Short lines are thermally limited, while long lines are security limited. The experimental DCTLs under study are assumed to be short lines, only limited by thermal ratings. 


\subsection{Short-term Emergency and Fault Duration}

The normal operating load of DCTL can be determined based on fault duration time and maximum conductor temperature for emergency rating to be allowable within the fault duration. Except for rare special cases such as old transmission lines built with lower dip criteria, the maximum temperature of conductor to specify emergency ratings is normally given as $100^{\circ} \mathrm{C}$ or $120^{\circ} \mathrm{C}$ for ACSR conductors, with maximum allowable temperature of $90{ }^{\circ} \mathrm{C}$. In the present research $120^{\circ} \mathrm{C}$ is taken into account for STER.

Figure 2 illustrates temperatures and ratings for different fault durations. Through the transient response of ACSR conductor, the initial temperature is pre-determined such that conductor temperature can reach the limit of $120^{\circ} \mathrm{C}$. The conductor current corresponding to this temperature can then be calculated; it is the maximum operating current of one circuit of DCTL, and the double-load of maximum operating current becomes a STER for the given fault duration. Several performances for short-term durations are summarized in Table I. If a short-term duration is chosen to be 5 minutes, one of the two circuits can allow the normal operating current of 1,724 A where the temperature theoretically reaches $91{ }^{\circ} \mathrm{C}$, which is not accepted as a practical rating since the maximum continuous temperature of ACSR should not exceed the normal operating temperature.
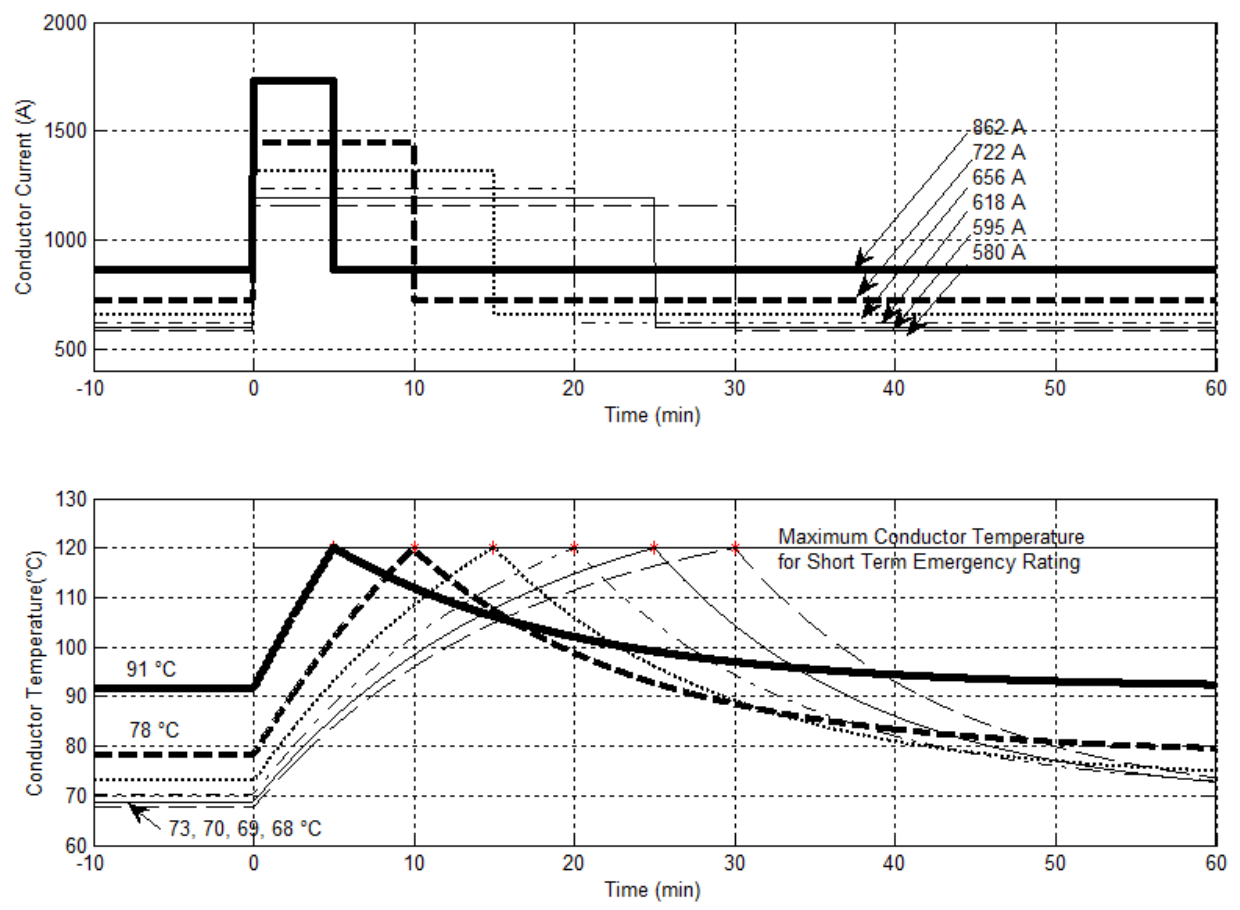

Figure 2. Load performance for different fault durations.

Table I - STER characteristics for different fault durations.

\begin{tabular}{|c|c|c|c|}
\hline $\begin{array}{c}\text { Fault Duration } \\
(\mathrm{min})\end{array}$ & $\begin{array}{c}\text { Normal Operation } \\
\text { Rating Temperature } \\
\left({ }^{\circ} \mathrm{C}\right)\end{array}$ & $\begin{array}{c}\text { Maximum } \\
\text { STER (A) }\end{array}$ & $\begin{array}{c}\text { Overload } \\
\text { Rate (\%) }\end{array}$ \\
\hline
\end{tabular}




\begin{tabular}{|c|c|c|c|}
\hline 5 & 91 & 1,724 & 203 \\
\hline 10 & 78 & 1,444 & 170 \\
\hline 15 & 73 & 1,312 & 155 \\
\hline 20 & 70 & 1,236 & 146 \\
\hline 25 & 69 & 1,190 & 140 \\
\hline 30 & 68 & 1,160 & 137 \\
\hline
\end{tabular}

Another limitation to select short-term duration is the dip criterion, which is a very significant key for conductor design temperature to be taken into account. Generally, maximum allowable conductor temperature is the maximum temperature limit to be selected in order to minimize annealing and loss of strength through the conductor life. Meanwhile, the maximum design conductor temperature is a temperature limit to be considered in order to guarantee a required dip when designing a line. Although there are various criteria or rules in designing ground clearance or towers, transmission lines built by several power companies were designed based on the maximum design temperature, $75{ }^{\circ} \mathrm{C}$ [13], [14], and it was applied to transmission lines in KEPCO starting in 1992 [10], [15]. Consequently, the short-term duration of 5 or 10 minutes may be unrealistic, despite showing a larger overload rating. However, in the case of selecting 15-minute duration, the line can carry $155 \%$ load of SLR without violating ground clearance. Finally, DCTL can be available to supply maximum current of 1,312 A for the two circuits, i.e., $656 \mathrm{~A}$ per circuit. In other words, it becomes the maximum normal operating current of DCTL under the given duration of 15 minutes for STER. Durations longer than 15 minutes can be used, but the maximum normal rating would be reduced which would limit the transmission line efficiency.

\subsection{Old Transmission Lines}

There are two important issues to be considered in case of transmission line design; one is to determine a suitable transmission capacity, and the other is to consider a suitable dip/clearance margin. Thermal line rating represents line current which corresponds to the maximum allowable conductor temperature for a particular line without clearance infringements, or significant loss in conductor tensile strength due to annealing [6], [13]. Transmission power has been traditionally limited by conductor thermal capacity defined in terms of SLR, based on a predetermined set of conditions. These conditions are incorporated into the line design to take ground clearance into account. All transmission lines are designed such that an acceptable ground clearance is maintained - at a certain design conductor temperature - according to the construction standards of the time. Thus, unless associated committees have recommended specific regulations, a default temperature of $75^{\circ} \mathrm{C}$ will be used to calculate both normal and emergency ratings of transmission lines [13].

Since the maximum allowable temperature of ACSR is $90{ }^{\circ} \mathrm{C}$, transmission lines have margins higher than SLR or clearances designed within the design temperature of conductor, $75{ }^{\circ} \mathrm{C}$. Normally most power utilities design transmission lines to be operated under the maximum conditions. However, in domestic transmission lines, ground clearances are usually required to have higher margins than design levels. As these criteria were 
established in different times, any specifications determined by such criteria may be unrealistic. Furthermore, there is a limit for the operating temperature or rating, and the maximum allowable temperature for such a transmission line may be restricted to the temperature at which the line can guarantee minimum clearance; sometimes it is selected below the maximum continuous-operating temperature of $90{ }^{\circ} \mathrm{C}$. In this paper it is defined as the limit-dip conductor temperature (LDCT), e.g., $86{ }^{\circ} \mathrm{C}$, and it is an estimated temperature by an old design criterion [15].

At the maximum allowable temperature of $86{ }^{\circ} \mathrm{C}$ for LDCT during a fault, some characteristics are summarized in Table II. Results are similar to those listed in Table I at 86 ${ }^{\circ} \mathrm{C}$, instead of $120{ }^{\circ} \mathrm{C}$. As the maximum temperature of conductor of this line is limited to 86 ${ }^{\circ} \mathrm{C}$, due to dip margin determined by design criteria, the maximum STER or operating current to be available is more restricted than the current for $120{ }^{\circ} \mathrm{C}$ given in Table I. For LDCT at $86{ }^{\circ} \mathrm{C}$ and $120{ }^{\circ} \mathrm{C}$ temperatures - for 15 -minute duration - the maximum STERs are $944 \mathrm{~A}$ and 1,312 A, respectively. As a result, the effectiveness of applying STER for DCTL would be reduced, which means that it may be possible for STER to apply to such old transmission line with a lower LDCT. The result implies that the effectiveness will be more limited for such old transmission lines in service. In order for the performances of STER to be improved in old lines, there are several actions to be taken such as increasing the tower height, replacing old conductors by high-temperature, low-sag conductors, or providing sufficient dip/ground clearance. Also, applying the dynamic line rating technique is considered a good strategy [13].

Table II - STER characteristics at limit-dip temperature of $86^{\circ} \mathrm{C}$.

\begin{tabular}{|c|c|c|c|}
\hline $\begin{array}{c}\text { Fault Duration } \\
(\mathrm{min})\end{array}$ & $\begin{array}{c}\text { Normal Operation } \\
\text { Rating Temperature } \\
\left({ }^{\circ} \mathrm{C}\right)\end{array}$ & $\begin{array}{c}\text { Maximum } \\
\text { STER (A) }\end{array}$ & $\begin{array}{c}\text { Overload } \\
\text { Rate (\%) }\end{array}$ \\
\hline 5 & 69 & 1,192 & 141 \\
\hline 10 & 64 & 1,026 & 121 \\
\hline 15 & 62 & 944 & 111 \\
\hline 20 & 60 & 865 & 106 \\
\hline 25 & 60 & 868 & 102 \\
\hline 30 & 59 & 848 & 100 \\
\hline
\end{tabular}

\subsection{Normal Operating Current Conditions}

In practical cases of applying emergency rating, there are various operating rules and related equipment in power systems. Hence, actions to be taken by the line operator during pre-contingency or post-contingency status are preset. When a line load is over LTER but below STER, within 15 minutes, suitable corrective procedures to solve the overloading of transmission line must be available. In general, such corrective steps may be load shedding, voltage reduction, or disconnecting the load [14]. Proper corrective actions can be only 'taken when the line fault or contingency is timely detected. For STER applications, it is a crucial key to detect the overload level and its duration period. By way of example, the fault 
duration is assumed to be 15 minutes and the emergency properties when varying conductor current are taken into consideration. If one circuit is broken at the beginning of fault, the other healthy circuit starts to carry twice the load from that instant, as shown in Figure 3. Conductor temperature at fault time begins to increase slowly until the end time of fault, which is the constant time preset by protection relay. The line automatically sheds the overload to another transmission-line bus, or reduces its rating.

At a normal operating current of $656 \mathrm{~A}$ and fault duration set to 15 minutes, the maximum allowable temperature of DCTL can be selected up to $120{ }^{\circ} \mathrm{C}$, even under worst weather conditions. However, if the line is operating normally with a load of 1,312 A and temperature of $73{ }^{\circ} \mathrm{C}$, the conductor temperature reaches $120{ }^{\circ} \mathrm{C}$ after 15 minutes. At this time, one circuit load - due to the fault - can be separated from the faulted transmission line to another line.

When protection relays are installed to detect fault time and to set fault duration, the conductor temperature does not increase up to the maximum allowable limit even for STER. For instance, let the initial conductor load be 1,200 A for the two circuits. If a fault occurs on one circuit at time $t_{1}$, the temperature of healthy conductor reaches $109{ }^{\circ} \mathrm{C}$, and the transmission line carries only $600 \mathrm{~A}$ of one circuit load while disconnecting the other $600 \mathrm{~A}$ load of the faulted circuit. If the protection relay is operated by presetting temperature limits - not by duration - in case of $600 \mathrm{~A}$ (or $500 \mathrm{~A}$ ) for initial operating loads, the time reached will be either 23.7 minutes or infinite, respectively, as given in Table III. Therefore, presetting a fault-clearing time may not be effective which implies that a faulted circuit on DCTL - with up to 500 A per circuit - can be operated without any corrective measures such as STER or LTER. However, the circuit must be designed with maximum operating temperature of $120^{\circ} \mathrm{C}$, when factors such as annealing and useful life of conductor are taken into consideration. According to analytical results for 500 A per circuit, the circuit may operate safely for such a faulted transmission line without any protection strategies. 

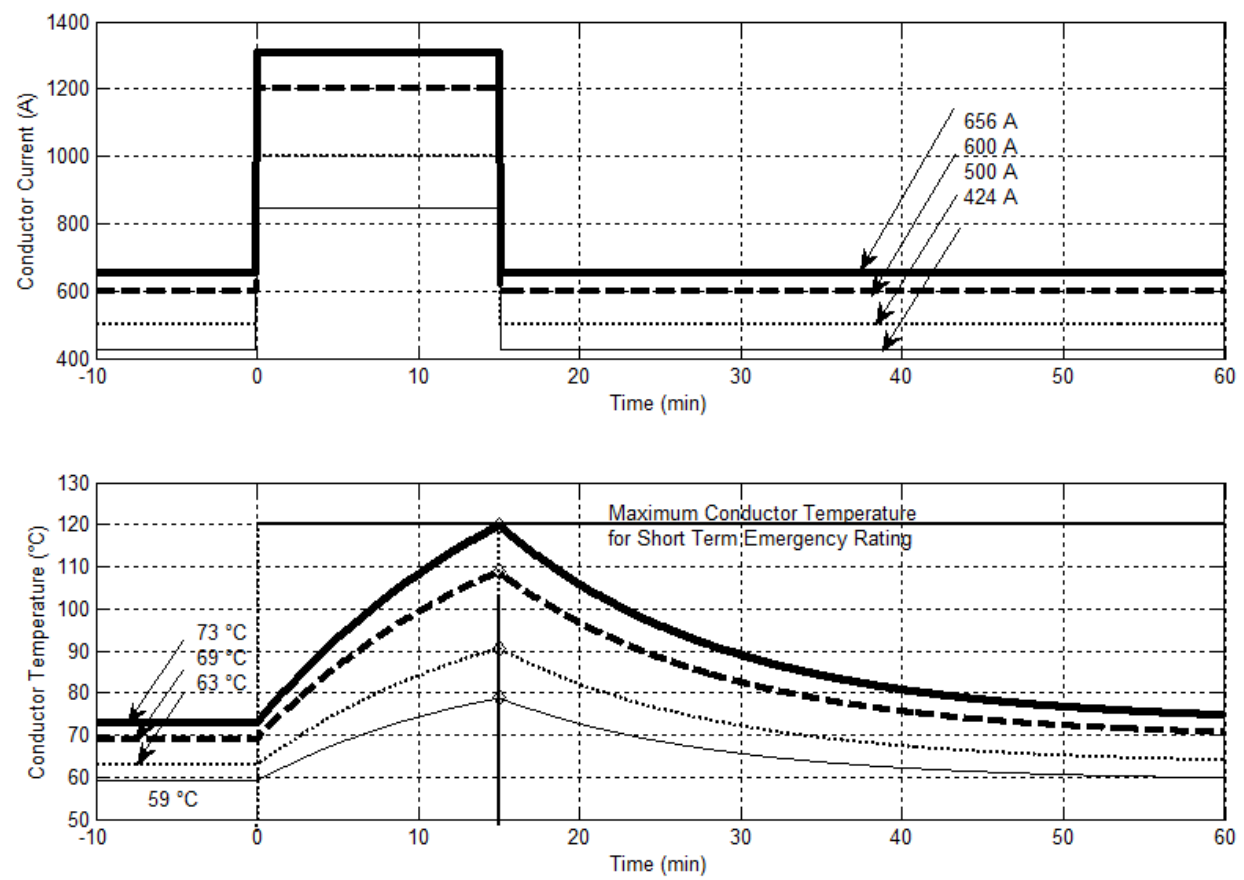

Figure 3. Load and transient characteristics as function of fault duration.

Table III - STER characteristics for different initial loads.

\begin{tabular}{|c|c|c|c|c|}
\hline $\begin{array}{c}\text { Initial } \\
\text { Conductor } \\
\text { Load (A) }\end{array}$ & $\begin{array}{c}\text { Initial Conductor } \\
\text { Temperature } \\
\left({ }^{\circ} \mathrm{C}\right)\end{array}$ & $\begin{array}{c}\text { Temperature at } \\
\text { Final Time } \\
\mathrm{t}_{\mathrm{f}}\left({ }^{\circ} \mathrm{C}\right)\end{array}$ & $\begin{array}{c}\text { Time at } \\
T_{120}(\mathrm{~min})\end{array}$ & $\begin{array}{c}\text { Overload } \\
\text { Rate }(\%)\end{array}$ \\
\hline 424 & 59 & 79 & $\infty$ & 100 \\
\hline 500 & 63 & 91 & $\infty$ & 118 \\
\hline 600 & 69 & 109 & 23.7 & 142 \\
\hline 656 & 73 & 120 & 15.0 & 155 \\
\hline
\end{tabular}

\subsection{Fault Examples}

In order to demonstrate the performance of emergency rating, an actual DCTL (described in Section 3.1 with its line voltage of $154 \mathrm{kV}$ and ACSR $410 \mathrm{~mm}^{2}$ bundle conductors) is analyzed. It is assumed that the transmission line was built according to old criterion with a limit-dip temperature of $86{ }^{\circ} \mathrm{C}$. The maximum operating load is preset at 1,888 A per circuit with bundle conductors, and is applied to STER with a duration of 15 minutes. To estimate the variation of conductor temperature with time, actual ambient temperatures and wind speeds monitored near the substation located at one end of the line were used. 

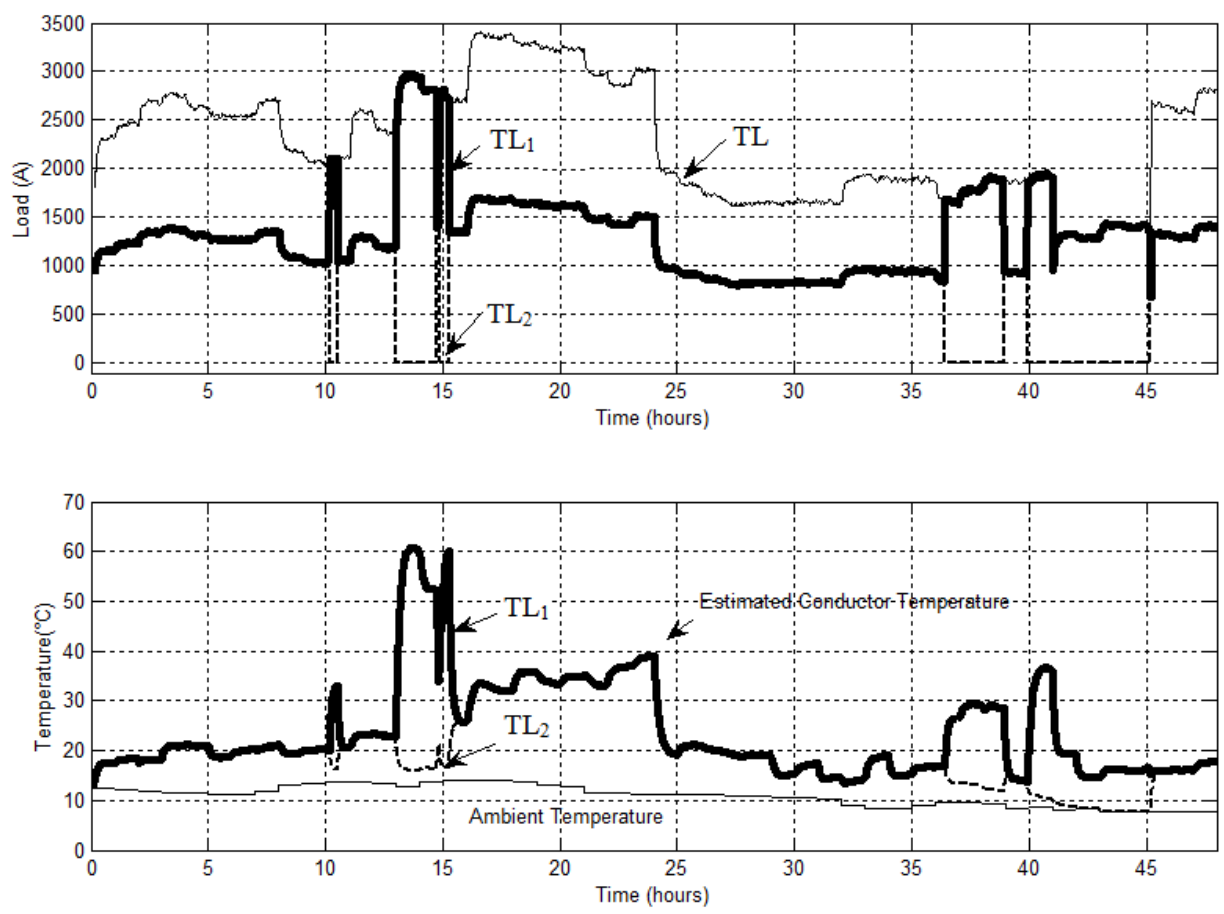

Figure 4. Example of applying STER to DCTL.

For simulation purposes, the two-day DCTL loads are assumed to be of increased levels more than the actually monitored loads, as shown in Figure 4(a), where $\mathrm{TL}_{1}$ and $\mathrm{TL}_{2}$ denote load curves of the two circuits, respectively. From the load curve it can be seen that $\mathrm{TL}_{1}$ operated under normal conditions, while for $\mathrm{TL}_{2}$ there were several contingencies. During these faults, the healthy circuit $\mathrm{TL}_{1}$ automatically carried double the load, as it was expected.

Conductor temperature can be estimated based on actual weather conditions, conductor type, load data, and geographic location. Conductor temperatures for $\mathrm{TL}_{1}$ and $\mathrm{TL}_{2}$ are calculated, as shown in Figure 4(b). As the time constant for ACSR conductors - when the load is changing - is expected to be approximately 15 minutes, it is known that all contingencies can last beyond the time constant. Therefore, the conductor temperature can reach any equilibrium levels. The first four faults went in progress during daylight, but the latest fault for 40 to 45 hours occurred in the evening. Therefore, $\mathrm{TL}_{2}$ during the last fault shows the same temperature - the ambient temperature - as time elapses.

$\mathrm{TL}_{1}$ carries double load over 15 minutes of a short-term emergency; however, its conductor temperature does not exceed the LDCT of $86{ }^{\circ} \mathrm{C}$ (or the maximum allowable conductor temperature for emergency rating). Therefore, the line can supply power with reliability and safety without violating ground clearance. According to the analytical results in Section 3.3, in such situation the line operates near the maximum operation rating and the temperature of the healthy conductor may reach $86{ }^{\circ} \mathrm{C}$ within the time period of short-term emergency. However, weather conditions such as ambient temperature and wind speed are not at their worst levels. As a result, the line shows up-rating load more than SLR, despite a short-term emergency. 


\section{Conclusions}

Double-circuit transmission lines (DCTLs) are used in the present study to apply and evaluate short-term emergency ratings. For a typical DCTL, it is assumed that even when one circuit of the line may become out of service, due to any fault or contingency, the healthy circuit begins to supply power continuously. The emergency rating will be generally used as the limiting rating to identify thermally limited conductors. Therefore, it is very important to determine emergency ratings, fault durations, and allowable temperature limits.

Considering annealing of conductor and its lifespan, a maximum allowable temperature of ACSR conductor can be selected to be $120{ }^{\circ} \mathrm{C}$ in order to apply a STER to DCTL. When the short-term duration of emergency rating is changed, the conductor current is calculated, which is defined as the maximum operating load of the line under normal operating conditions. Furthermore, an application of STER to some old transmission lines (built according to past design criteria) with a lower dip/ground clearance margin is analyzed. In such transmission lines, maximum conductor temperature could be restricted to a limit-dip temperature, i.e., $86{ }^{\circ} \mathrm{C}$. Normal operating current when fault duration was preset and maximum operating current - when varying maximum allowable conductor temperature are also discussed. The focus was on designing emergency ratings with short-term duration. Both the efficiency and possibility of applying STER to DCTL are presented.

\section{References}

1. Holbert, K.E., and Heydt, G.T., "Prospects for dynamic transmission circuit ratings," Proc. IEEE International Symposium on Circuits and Systems Conference, Sydney, Australia, vol. 3, pp. 205-208, 2001.

2. Pytlak, P., Musilek, P., and Lozowski, E., "Precipitation-based conductor cooling model for dynamic thermal rating systems," Proc. IEEE Electrical Power \& Energy Conference, Montreal, Canada, pp. 1-7, 2009.

3. IEEE Standard 738, IEEE Standard for Calculating the Current-Temperature of Bare Overhead Conductors, 2006.

4. Douglas, D.A., and Edris, A.A., "Real-time monitoring and dynamic thermal rating of power transmission circuits," IEEE Trans. Power Delivery, vol. 11, no. 3, pp. 14071418, 1996.

5. Ren, L., Xiuchen, J., and Gehao, S., "Research for dynamic increasing transmission capacity," Proc. International Conference on Condition Monitoring and Diagnosis, Beijing, China, pp. 720-722, 2008.

6. NYSEG and RG\&E Transmission Planning Criteria, System Planning, July 2009.

7. Facility Rating Methodology and Communication for Associated Electric Cooperative, Inc., NERC Standard-FAC-008-1 and FAC-009-1, 2009.

8. Aggarwal, R.K., Xuan, Q.Y., Dunn, R.W., Johns, A.T., and Bennett, A., “A novel fault classification technique for double-circuit lines based on a combined unsupervised/supervised neural network," IEEE Trans. Power Delivery, vol. 14, no. 4, pp.1250-1256, 1999.

9. Korres, G.N., and Apostolopoulos, C.A., "Precise fault location algorithm for double circuit transmission lines using unsynchronized measurements from two anti-parallel ends," IET Generation, Transmission, and Distribution, vol. 4, no. 7, pp. 824-835, 2010. 
10. Operation Criteria of Short-time Transient Rating for KEPCO's Transmission Lines, Research Report, R-2005-7-331, KERI, 2009.

11. Apostolov. A., Tholomier, D., Sambasivan, S., and Richards, S., "Protection of doublecircuit transmission lines," Proc. 60 ${ }^{\text {th }}$ Annual Conference for Protective Relay Engineers, College Station, TX, pp. 85-101, 2007.

12. Design Standard for Dip of Overhead Transmission Lines, DS 1211, KEPCO, 2004.

13. Carrington, R.J., "New technologies for transmission line up-rating," Proc. $8^{\text {th }}$ Transmission \& Distribution Construction, Operation \& Live-Line Maintenance Conference, Orlando, FL, pp. 311-318, 1998.

14. Rahim, A.A., Abidin, I.Z., Tarlochan, F., and Hashim, M.F., "Thermal rating monitoring of the TNB overhead transmission line using line ground clearance measurement and weather monitoring techniques," Proc. $4^{\text {th }}$ International Conference of Power Engineering and Optimization Conference, Shah Alam, Malaysia, pp. 274-280, 2010.

15. Design Standard for Ground Clearance of Overhead Transmission Lines, DS 1020, KEPCO, 2003. 